\title{
Features of tsunamis in the ports of the Sakhalin Region inferred from the data of instrumental measurements and numerical modeling
}

\section{G. V. Shevchenko}

A. V. Loskutov
Institute of Marine Geology and Geophysics, FEB RAS, Yuzhno-Sakhalinsk, Russia

The characteristics of waves processes in ports of Sakhalin and the Kuril Islands inferred from instrumental measurements by autonomous bottom pressure gauges deployed by the Institute of Marine Geology and Geophysics (IMGG FEB RAS) and Sakhalin Tsunami Warning Service are considered. The greatest attention is paid to the analysis of waveforms of two strong recent tsunamis: Chilean 27.02.2010 and Tohoku 11.03.2011, which posed a danger for the settlements of the island region. It is shown that the peculiarities of the transformation of the tsunami wave field and the main threat to ships and hydrotechnical structures located in ports are largely determined by resonance oscillations - seiches. The main periods of resonance oscillations are estimated, their spatial structure (the position of antinodes and nodal lines) is studied using numerical simulation. As a rule, the maximum amplitudes of the seiches are observed in remote parts of bays and harbors, which are traditionally considered to be the safest. The following examples show that this opinion, valid for storm surge, is erroneous in assessing tsunami hazard. The results of the research can be useful in planning the reconstruction of ports and developing measures to improve the safety of navigation.

\section{Keywords}

Port, Bay, Harbor, Tsunami, Wave height, Wave period, Spectrum

\section{References}

For citation: Shevchenko G.V., Loskutov A.V. Features of tsunamis in the ports of the Sakhalin Region inferred from the data of instrumental measurements and numerical modeling. Geosystems of Transition Zones, 2017, vol. 1, N 2, p. 35-49. doi:10.30730/2541-8912.2017.1.2.035-049 